\title{
Chromium doped copper vanadates photoanodes for water splitting
}

\author{
Drialys Cardenas-Morcoso, Anna Peiro-Franch, Isaac Herraiz-Cardona, Sixto \\ Gimenez* \\ Institute of Advanced Materials (INAM), Universitat Jaume I, 12006 Castelló, Spain \\ *Corresponding author: sjulia@uji.es
}

12 October 2016

\begin{abstract}
Solar hydrogen obtained from photoelectrochemical water splitting offers a versatile approach towards the substitution of fossil fuels by decentralized and sustainable resources, like water and sun. In the present study we have investigated the Chromium doped Copper Vanadate $\left(\mathrm{Cr}: \mathrm{Cu}_{3} \mathrm{~V}_{2} \mathrm{O}_{8}\right)$ as a candidate photoanode for photoelectrochemical water splitting. We have synthetized this material through a simple aqueous precipitation reaction, which easily allows compositional modifications. We have studied the effect of extrinsic doping with substitutional atoms like Chromium on the optical and photoelectrochemical properties. The main limiting factor for performance is related to the high bulk recombination, which is partially overcome by 0.75 at. \% Chromium doping, with a five-fold enhancement of the charge separation efficiency at $1.23 \mathrm{~V}$ vs RHE. Despite this remarkable milestone, significant further improvement is needed for the technological exploitation of this material.
\end{abstract}

Keywords: water splitting, photoanode, copper vanadate, chromium doping 


\section{Introduction}

The sun feeds the planet with an enormous amount of power, $120000 \mathrm{TW}$, that considerably exceeds the projected global energy demand for the next decades ( $\sim 30$ TW by 2050) in a moderate scenario.[1] Therefore, the conversion of sunlight into a profitable form of energy is almost mandatory to meet the needs of a growing world population with increasing living standards. Photoelectrochemical (PEC) water splitting offers an attractive technology for the conversion and storage of solar energy as chemical energy in the form of molecular bonds. In this process, the water molecule is decomposed into $\mathrm{H}_{2}$ and $\mathrm{O}_{2}$ under solar illumination. The $\mathrm{O}_{2}$ evolution reaction (OER) is thermodynamically and kinetically more demanding, since four holes per molecule of produced oxygen are required. The strong oxidizing conditions needed for this reaction, severely limit the choice of adequate materials for viable operation. Consequently, the development of efficient and stable oxygen evolving photoanodes is one of the key challenges to success of this technology.[2, 3]

Since the pioneering study of Fujishima and Honda demonstrating UV light-assisted water splitting with $\mathrm{TiO}_{2}$,[4] intensive research efforts have been carried out to find earthabundant, efficient, stable and cost-effective materials that can absorb a significant fraction of the solar spectrum to split water. Metal oxides or oxo-metalates based on abundant materials, such as $\mathrm{TiO}_{2},[4,5] \mathrm{Fe}_{2} \mathrm{O}_{3},[6] \mathrm{WO}_{3},[7] \mathrm{ZnO},[8]$ and $\mathrm{BiVO}_{4},[9,10]$ have been explored as candidate photoanode materials, satisfying both stability and cost requirements. Nevertheless, the low performance of these photoanodes attributed to poor electronic properties $\left(\mathrm{Fe}_{2} \mathrm{O}_{3}\right.$ and $\left.\mathrm{BiVO}_{4}\right)$ and/or large bandgaps $\left(\mathrm{TiO}_{2}, \mathrm{WO}_{3}\right.$ and $\left.\mathrm{ZnO}\right)[11]$ hinder their large-scale use in PEC systems. In order to overcome these problems, different strategies have been accomplished, involving combinatorial synthesis,[12] tuning the band structure of semiconductor materials by doping with different elements, [13, 14] surface 
state passivation, $[15,16]$ surface activation with OER catalysts, $[17,18]$ and nanostructuring.[19-22]

At present, metal vanadates, mainly $\mathrm{BiVO}_{4}$, are at the forefront of the research for PEC water splitting photoanodes.[13, 23, 24] A record photocurrent of $6.72 \mathrm{~mA} \cdot \mathrm{cm}^{-2}$ at $1.23 \mathrm{~V}$ vs RHE was obtained for $\mathrm{BiVO}_{4}$, close to its theoretical maximum value $\left(7.5 \mathrm{~mA} \cdot \mathrm{cm}^{-2}\right)$, by means of combining nanostructuring with adequate OER catalysts.[25] Triclinic $\mathrm{NiV}_{2} \mathrm{O}_{6}$ films, fabricated by a vacuum deposition technique, have been recently tested for the first time as photoanodes for water oxidation. Although the observed photocurrent is relatively low (ca. $0.25 \mathrm{~mA} \cdot \mathrm{cm}^{-2}$ at $1.23 \mathrm{~V}$ vs RHE) according to the band gap $(\sim 2.4 \mathrm{eV})$ both the wide availability of the semiconductor components ( $\mathrm{Ni}$ and $\mathrm{V}$ ) and its stability in alkaline conditions postulate this material as a promising anode for PEC systems.[26]

Similar to $\mathrm{NiV}_{2} \mathrm{O}_{6}, \mathrm{Cu}_{3} \mathrm{~V}_{2} \mathrm{O}_{8}$ is an n-type semiconductor composed only of first-row transition metals. Although it has been previously examined for different applications (Li-ion batteries and degradation of organic pollutants), $[27,28]$ both, its bandgap near 2 $\mathrm{eV}$ and the adequate position of the valence band maximum make this material suitable for water photo-oxidation. To the best of our knowledge, there is only one recent study reporting the PEC performance of $\mathrm{Cu}_{3} \mathrm{~V}_{2} \mathrm{O}_{8}$ photoanodes. Seabold and Neale obtained a photocurrent of ca. $5 \mu \mathrm{A} \cdot \mathrm{cm}^{-2}$ at $1 \mathrm{~V}$ vs RHE in $0.1 \mathrm{M}$ potassium borate buffer at $\mathrm{pH} 9.2$ for bare $\mathrm{Cu}_{3} \mathrm{~V}_{2} \mathrm{O}_{8}$ samples synthesized from the precipitation of nanoparticles of a simple hydroxide precursor. Also, it was found that doping with 0.75 at $\%$ Mo yielded an improvement of $40 \%$ in photocurrent, as a consequence of an increase in the electron diffusion length.[29] More recently, two different copper-based metal vanadates, i.e. $\mathrm{CuV}_{2} \mathrm{O}_{6}$ and $\mathrm{Cu}_{2} \mathrm{~V}_{2} \mathrm{O}_{7}$, were also reported as photoanodes for water splitting achieving photocurrent densities about 25 and $35 \mu \mathrm{A} \cdot \mathrm{cm}^{-2}$, respectively, at $1.23 \mathrm{~V}$ vs RHE in 0.1 M sodium borate buffer solution.[30] In both studies, it was highlighted that the main 
limitation of $\mathrm{Cu}$-based vanadate materials for PEC performance is related to the low charge separation efficiency. On the other hand, vanadate compounds suffer from rapid corrosion due to the anodic dissolution of $\mathrm{V}$ species. Zhou et al. demonstrated that, in copper vanadate, the $\mathrm{V}$ corrosion is mitigated through a self-passivation process in which $\mathrm{V}$ corrodes from the film, leaving behind a $\mathrm{Cu}$-rich oxide surface layer that prevents further $\mathrm{V}$ corrosion.[31] This investigation confirms that copper vanadate has indeed emerged as a promising photoanode for water splitting due to its stability, particularly in weakly alkaline borate electrolytes.

In the present work, we report our efforts aiming at improving the charge transport and charge separation efficiency of this semiconductor material. We have employed a synthetic method inspired on that previously reported.[29] This material was doped with chromium $\left(\mathrm{Cr}: \mathrm{Cu}_{3} \mathrm{~V}_{2} \mathrm{O}_{8}\right)$, which has an atomic radii of $0.74 \AA$, close to that of $\mathrm{Cu}^{2+}(0.73 \AA)$, making feasible the exchange of both atoms in the $\mathrm{CuO}_{6}$ octahedra of its crystalline structure, enhancing the extrinsic n-type doping of the semiconductor oxide. A detailed optoelectronic and photoelectrochemical characterization has been performed to quantitatively assess the contribution of the three fundamental processes involved in PEC, i.e. charge carrier generation, charge transport to the semiconductor-liquid interface and interfacial charge transfer, to the obtained photocurrent.

\section{Materials and methods}

\subsection{Materials and synthesis}

Preparation of nanoparticles of $\mathrm{Cu}_{3} \mathrm{~V}_{2} \mathrm{O}_{7}(\mathrm{OH})_{2} \cdot 2 \mathrm{H}_{2} \mathrm{O}$ was carried out following the procedure described in reference [29], with slight modifications, using as reagents: $\mathrm{NH}_{4} \mathrm{VO}_{3}$ (ASC reagent, $\geq 99.0 \%$, Sigma-Aldrich) and $\mathrm{Cu}\left(\mathrm{CH}_{3} \mathrm{COO}\right)_{2} \cdot \mathrm{H}_{2} \mathrm{O}$ (puriss. p.a. $\geq 99.0 \%$, Sigma-Aldrich). According to this, an initial $\mathrm{Cu}_{3} \mathrm{~V}_{2} \mathrm{O}_{7}(\mathrm{OH})_{2} \cdot 2 \mathrm{H}_{2} \mathrm{O}$ nanoparticles 
suspension was prepared by a simple precipitation reaction synthesis. The precursor was recovered by successive centrifugation at $4000 \mathrm{rpm}$ for $6 \mathrm{~min}$ and washing with absolute ethanol and finally re-suspended in $20 \mathrm{~mL}$ of ethanol. From this solution, a fraction was taken and diluted to obtain a $0.22 \mathrm{M}$ copper content solution. Also, a drop of Triton X-100 was added in order to enhance the homogeneity of the deposition. $\mathrm{Cr}_{2} \mathrm{Cu}_{3} \mathrm{~V}_{2} \mathrm{O}_{7}(\mathrm{OH})_{2} \cdot 2 \mathrm{H}_{2} \mathrm{O}$ nanoparticles were prepared by adding the required amount of $0.22 \mathrm{M} \mathrm{CrCl}_{3} \cdot 6 \mathrm{H}_{2} \mathrm{O}$ (p.a. $\geq 98 \%$ ) solution into $10.0 \mathrm{~mL}$ of $\mathrm{Cu}_{3} \mathrm{~V}_{2} \mathrm{O}_{7}(\mathrm{OH})_{2} \cdot 2 \mathrm{H}_{2} \mathrm{O}$ suspension in order to obtain the desired $\mathrm{Cr}: \mathrm{Cu}$ ratio (e.g. $75 \mu \mathrm{L}$ of $\mathrm{CrCl}_{3} \cdot 6 \mathrm{H}_{2} \mathrm{O}$ for $0.75 \%$ of $\mathrm{Cr}$ content).

Fluorine doped tin oxide (FTO) coated glass electrodes of $3.0 \times 1.0 \mathrm{~cm}^{2}$ area were washed by successive ultra-sonication for 15 min in soap (Hellmanex), Milli-Q water, ethanol, acetone and isopropanol and dried with compressed air. Before the deposition of the nanoparticles, the FTO substrates were treated in a $\mathrm{UV}-\mathrm{O}_{3}$ chamber for $15 \mathrm{~min}$. Films of different thickness were prepared by spin coating a different number of layers of the $\mathrm{Cu}_{3} \mathrm{~V}_{2} \mathrm{O}_{7}(\mathrm{OH})_{2} \cdot 2 \mathrm{H}_{2} \mathrm{O}$ precursor on the FTO glass. Spin coating was carried out at 3000 rpm for $30 \mathrm{~s}$, using $40 \mu \mathrm{L}$ of precursor for each deposited layer. These films were dried on a hot plate preheated to $200{ }^{\circ} \mathrm{C}$ for 2 min and then annealed at $425^{\circ} \mathrm{C}$ for $1 \mathrm{~h}$, preceded by a $2 \mathrm{~h}$ ramp up to obtain dark orange oxide films.

\subsection{Structural, optical and photoelectrochemical characterizations}

X-ray diffraction (XRD) data were obtained employing $\mathrm{Cu} \mathrm{K} \alpha$ radiation at room temperature, scanning the samples from $10^{\circ}$ to $70^{\circ}(2 \theta)$ with a step of $0.02^{\circ}$. The morphology and thickness of both the precursor and oxide films were determined by scanning electron microscopy (SEM) using a JEOL JEM-3100F field emission scanning electron microscope. UV-Vis absorption spectra were recovered with a Cary 300 UV-Vis Varian spectrophotometer, between 300 and $800 \mathrm{~nm}$. The absorbance (A) was estimated from transmittance $(\mathrm{T})$ and diffuse reflectance (R) measurements as: $A=$ 
$-\log (T+R)$. The indirect optical bandgap was estimated by the Tauc plot as: $(h v \alpha)^{1 / n}=A\left(h v-E_{g}\right)$. In this expression, the absorption coefficient $(\alpha)$ was calculated by $A=\alpha l$, where $l$ is the thickness of the electrode.

Photoelectrochemical (PEC) measurements were performed using a PGSTAT302N potentiostat from AutoLab in a three-electrode configuration, with a Pt wire as counter electrode and $\mathrm{Ag} / \mathrm{AgCl}, \mathrm{KCl}(3 \mathrm{M})$ as reference electrode, in a buffer of $0.1 \mathrm{M} \mathrm{H}_{3} \mathrm{BO}_{3}$ ( $\geq 99.8 \%$, Riedel-deHäen) adjusted to $\mathrm{pH} 9.2$ using KOH. In some cases, a fraction of 0.1 $\mathrm{M} \mathrm{Na} \mathrm{SO}_{3}(\geq 98 \%$, Sigma-Aldrich) was added to the borate buffer as sacrificial hole scavenger to suppress undesirable surface recombination reactions $[32,33]$ and increase the hole transfer kinetics at the semiconductor/liquid interface. The scan rate for cyclic voltammetry measurements was $50 \mathrm{mV} \mathrm{s}^{-1}$. Photocurrent measurements were recorded under AM1.5 $100 \mathrm{~mW} / \mathrm{cm}^{2}$ using a Xe lamp previously calibrated with an NRELcalibrated Si solar cell. In all cases, reported potential (E) was referred to the reversible hydrogen electrode (RHE) through the Nernst equation: $E_{R H E}=E_{A g / A g C l}+0.059 \mathrm{~V} \times$ $p H$. The same experimental setup was employed for chronoamperometric measurements, which were performed at $1.23 \mathrm{~V}$ vs RHE for $1 \mathrm{~h}$. For impedance spectroscopy (IS), a 20 $\mathrm{mV}$ amplitude sinusoidal perturbation at frequencies between $0.01 \mathrm{~Hz}$ and $1 \mathrm{MHz}$ was used. Mott-Schottky analysis was performed in the dark at different frequencies $(10 \mathrm{~Hz}, 50$ $\mathrm{Hz}$ and $100 \mathrm{~Hz}$ ). Incident photon-to-current efficiency (ICPE) was measured by employing a $300 \mathrm{~W}$ Xe lamp coupled to a monochromator. The photoelectrode was polarized at the desired voltage and the photocurrent was measured using an optical power meter 70310 from Oriel Instruments. A Si photodiode was used to measure the light intensity to calibrate the system. IPCE was calculated with the expression: IPCE $\%=\frac{I_{p h}(A)}{P(W)} \times \frac{1239.8}{\lambda(n m)} \times$ 100. 


\section{Results and discussion}

In order to optimize both the homogeneity and reproducibility for the preparation of the oxide films, the deposition of the precursor solution was rigorously controlled. In first place, the synthesis of the precursor by a precipitation reaction provided a very easy and versatile way to control both the doping density and the concentration of nanoparticles in the precursor solution. On the other hand, spin coating proved to be the most reproducible method to obtain different film thicknesses by controlling the number of deposited layers of the same volume and concentration. Film thicknesses of $400 \mathrm{~nm}, 600 \mathrm{~nm}$ and $800 \mathrm{~nm}$ were obtained for 2, 3 and 4 deposited layers, respectively, for the precursor and final oxide films (see Supplementary Information, Fig. SI1). Deposition of more than four layers of precursor resulted in inhomogeneous films. The crystalline structure of the $\mathrm{Cu}_{3} \mathrm{~V}_{2} \mathrm{O}_{7}(\mathrm{OH})_{2} \cdot 2 \mathrm{H}_{2} \mathrm{O}$ precursor was confirmed by XRD analysis, (Fig. 1). The crystalline system is monoclinic with space group $\mathrm{C} 2 / \mathrm{m}$, and no secondary phases were observed. The structure of the final oxides was also confirmed as monoclinic (space group P21/c) in good agreement with the reference pattern. The effect of the incorporation of chromium on the crystalline structure was also studied. No representative changes due to the presence of new phases or different peak intensity ratios were detected. However, a slight shift of the [012] peak position $\left(2 \theta=32.2^{\circ}\right)$ with the increase in chromium content is noted, particularly at the highest $\mathrm{Cr}$ concentration (1.5\%), as depicted in Fig. 1. These shifts are directly related to the interplanar distance through the Bragg's equation $2 \mathrm{~d}_{\mathrm{hkl}} \operatorname{sen} \theta_{\mathrm{hkl}}=\mathrm{n} \lambda$, demonstrating the incorporation of chromium in the crystalline lattice. 


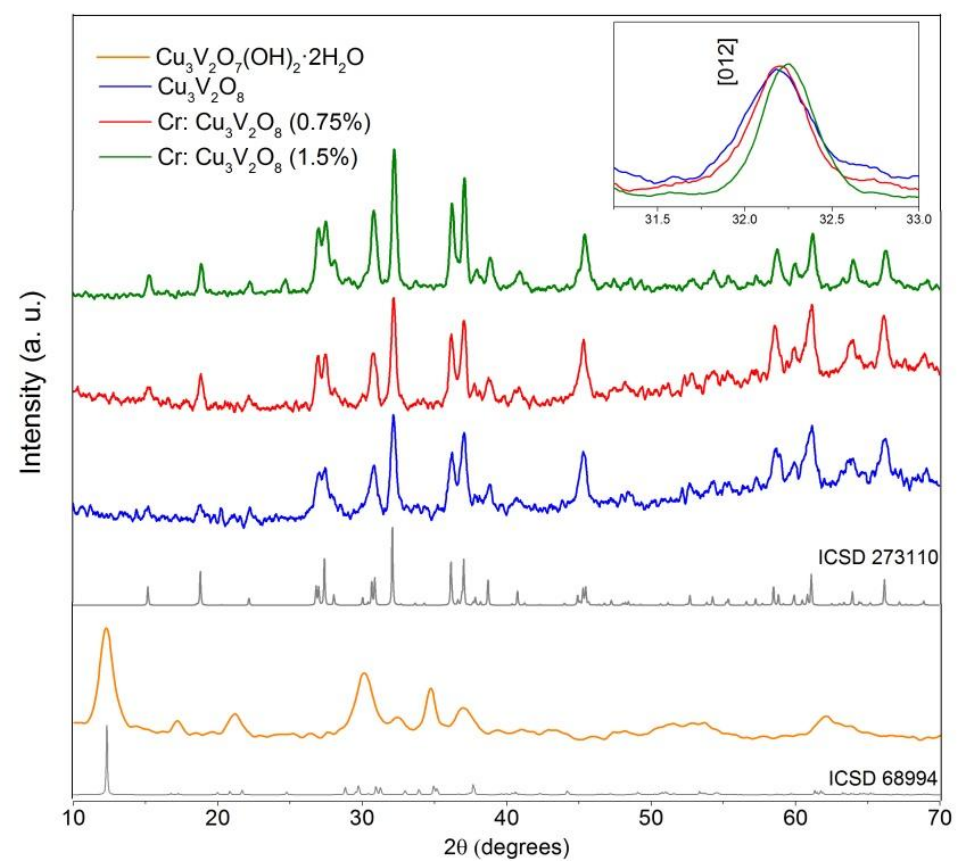

Fig. 1. $\mathrm{XRD}$ spectra of $\mathrm{Cu}_{3} \mathrm{~V}_{2} \mathrm{O}_{7}(\mathrm{OH})_{2} \cdot 2 \mathrm{H}_{2} \mathrm{O}, \mathrm{Cu}_{3} \mathrm{~V}_{2} \mathrm{O}_{8}$ and $\mathrm{Cr}: \mathrm{Cu}_{3} \mathrm{~V}_{2} \mathrm{O}_{8}$ powders. The reference patterns for these phases are also included: ICSD 68994 for $\mathrm{Cu}_{3} \mathrm{~V}_{2} \mathrm{O}_{7}(\mathrm{OH})_{2} \cdot 2 \mathrm{H}_{2} \mathrm{O}$ precursor and ICSD 273110 for $\mathrm{Cu}_{3} \mathrm{~V}_{2} \mathrm{O}_{8}$. The inset graph shows an amplification of the maximum corresponding to the [012] direction to clearly illustrate the $2 \theta$ shift with Cr doping.

The morphology and particle size was determined by SEM (Fig. 2). The films of the precursor were composed of nanoflakes with around 70-80 nm size (Fig. 2a). In contrast, after annealing, both undoped and Cr-doped nanoparticles showed a globular morphology (Fig. 2b and c), with lower particle size for the doped nanoparticles (approximately 40-100 $\mathrm{nm}$ vs $20-80 \mathrm{~nm}$, respectively) at the optimum $\mathrm{Cr}$ concentration $(0.75 \%)$.
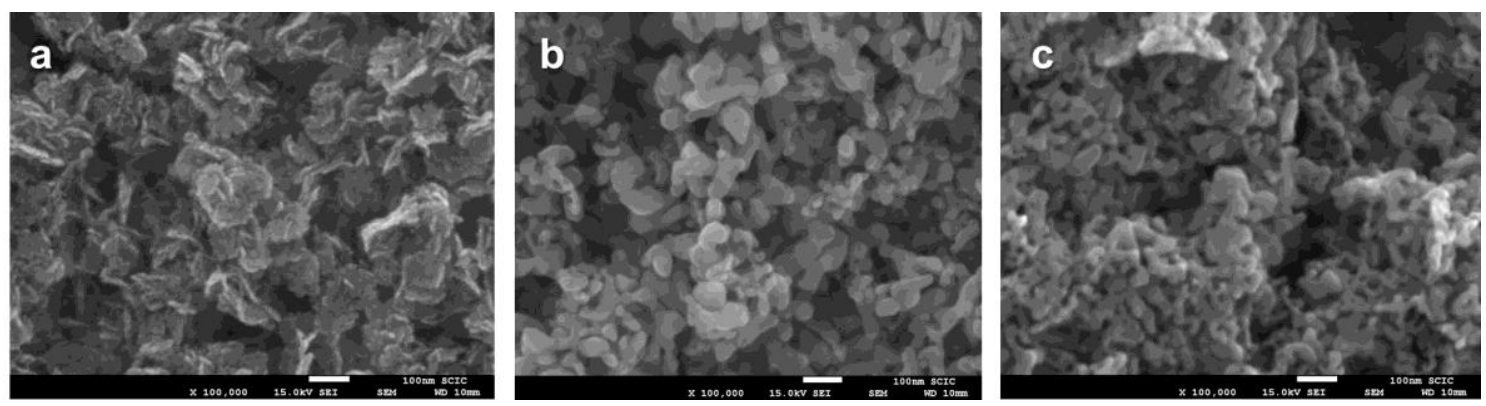
Fig. 2. Top-view micrographs of $\mathrm{Cu}_{3} \mathrm{~V}_{2} \mathrm{O}_{7}(\mathrm{OH})_{2} \cdot 2 \mathrm{H}_{2} \mathrm{O}$ (a), $\mathrm{Cu}_{3} \mathrm{~V}_{2} \mathrm{O}_{8}$ (b), and $\mathrm{Cr}: \mathrm{Cu}_{3} \mathrm{~V}_{2} \mathrm{O}_{8}(0.75 \%)$ (c) obtained by SEM. Film thickness: $800 \mathrm{~nm}$

The optical properties of the $\mathrm{Cu}_{3} \mathrm{~V}_{2} \mathrm{O}_{8}$ films with different thickness values are summarized in Fig. 3a. The absorbance increases monotonically with film thickness as expected, and the films can absorb light up to approximately $600 \mathrm{~nm}$. Fig. $3 \mathrm{~b}$ shows the effect of Cr doping on the optical properties, clearly indicating that the optical response of the $\mathrm{Cu}_{3} \mathrm{~V}_{2} \mathrm{O}_{8}$ films are not significantly modified after doping (Fig. SI2 illustrates this effect for all thickness values). The inset in Fig. $3 \mathrm{~b}$ shows the Tauc plot for indirect transitions, and the calculated indirect bandgap for both undoped and doped $\mathrm{Cu}_{3} \mathrm{~V}_{2} \mathrm{O}_{8}$ films $(2.0 \mathrm{eV})$ is in excellent agreement with that previously reported.[29]

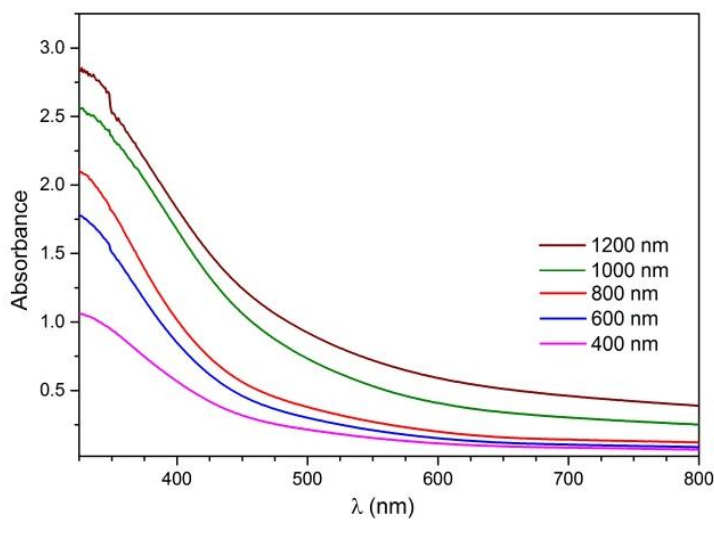

(a)

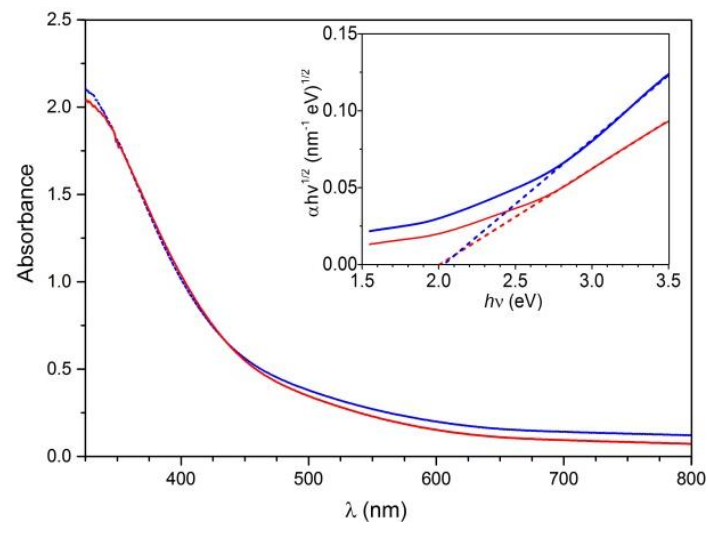

(b)

Fig. 3. (a) Absorbance of $\mathrm{Cu}_{3} \mathrm{~V}_{2} \mathrm{O}_{8}$ with different thickness values. (b) Absorbance spectra of $\mathrm{Cu}_{3} \mathrm{~V}_{2} \mathrm{O}_{8}$ (blue) and $\mathrm{Cr}_{2} \mathrm{Cu}_{3} \mathrm{~V}_{2} \mathrm{O}_{8}(0.75 \%$ ) (red) films of $800 \mathrm{~nm}$ thickness. Inset: Tauc plots for the determination of the indirect bandgap transition $(2.0 \mathrm{eV})$.

In order to evaluate both the optimum thickness and $\mathrm{Cr}$ concentration of the films, the functional performance as oxygen evolving photoanodes was characterized by the $\mathrm{j}-\mathrm{V}$ curves of doped and undoped $\mathrm{Cu}_{3} \mathrm{~V}_{2} \mathrm{O}_{8}$ photoanodes in the dark and under illumination at $100 \mathrm{~mW} \cdot \mathrm{cm}^{-2}$ in a borate buffer solution ( $\mathrm{pH}$ 9.2), as compiled in Fig. 4. Fig. 4.a shows that the $800 \mathrm{~nm}$ thick samples yield the best performance, which can be attributed to the 
inhomogeneous material distribution as the number of spin coating cycles increases. With respect to the $\mathrm{Cr}$ content, the optimum doping concentration appears at $0.75 \%$, which means a three-fold enhancement at $1.5 \mathrm{~V}$ vs $\mathrm{RHE}$ compared to pristine $\mathrm{Cu}_{3} \mathrm{~V}_{2} \mathrm{O}_{8}$ (Fig. $4 \mathrm{~b}$ ). Dopant concentrations higher than $0.75 \%$ (i.e. $1 \%$ and $1.5 \%$ ) did not improve the obtained photocurrent, as showed in the inset on Fig. 4b.

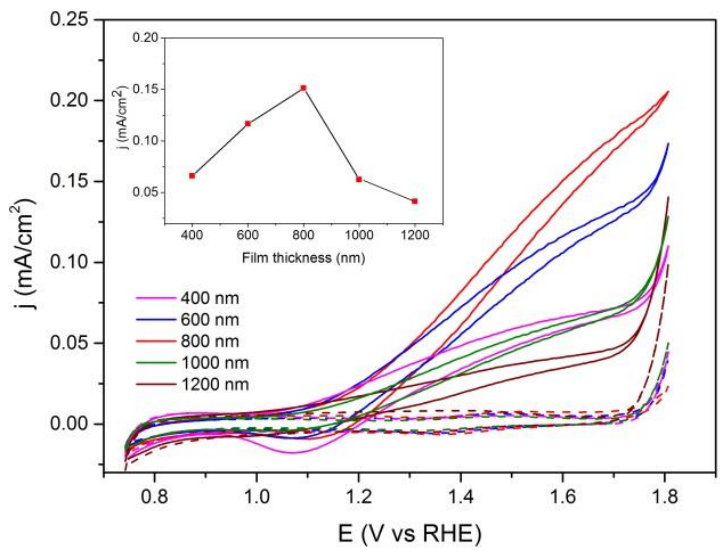

(a)

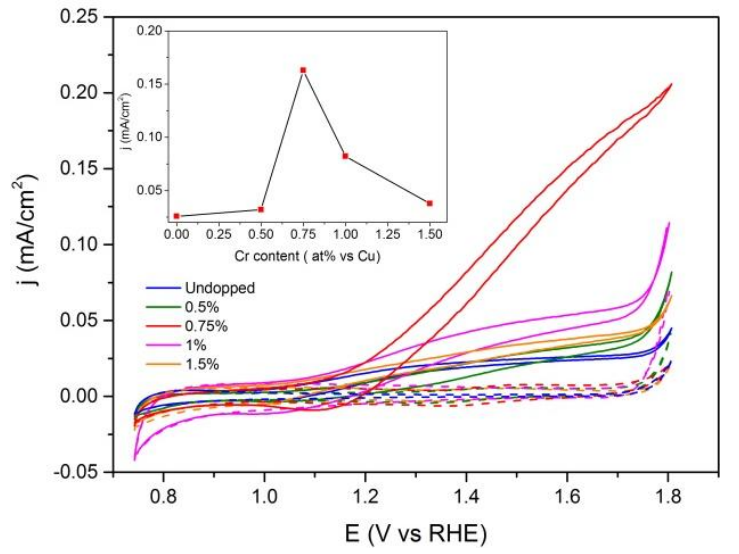

(b)

Fig. 4. j-V curves of undoped and $\mathrm{Cr}$-doped $\mathrm{Cu}_{3} \mathrm{~V}_{2} \mathrm{O}_{8}$ films in borate buffer at $\mathrm{pH} 9.2$ in the dark (dashed lines) and under front-side illumination at $100 \mathrm{~mW} \cdot \mathrm{cm}^{-2}$ (dashed lines). (a) Effect of thickness $(0.75 \% \mathrm{Cr}$ content). (b) Effect of $\mathrm{Cr}$ loading (800 $\mathrm{nm}$ thickness). Insets in (a) and (b) indicate the photocurrent at $1.54 \mathrm{~V}$ for different film thickness and $\mathrm{Cr}$ concentration, respectively.

Fig. 5a and $\mathrm{b}$ show the $\mathrm{j}-\mathrm{V}$ curves for the optimum $\mathrm{Cr}$ concentration and film thickness in borate buffer at $\mathrm{pH} 9.2$ in the dark and under front illumination with and without a hole scavenger $\left(0.1 \mathrm{M} \mathrm{Na}_{2} \mathrm{SO}_{3}\right)$ added to the solution, respectively. This sacrificial agent was employed to minimize the surface limitations of the material. The obtained photocurrent for sulfite oxidation is increased from 66 to $100 \mu \mathrm{A} \cdot \mathrm{cm}^{-2}$ at $1.0 \mathrm{~V}$ vs RHE due to the $\mathrm{Cr}$ doping. The enhancement reported again for the $\mathrm{Cr}_{2} \mathrm{Cu}_{3} \mathrm{~V}_{2} \mathrm{O}_{8}$ film indicates that, as a result of the doping process, there is not a significant improvement in the surface catalytic 
properties of the photoanode, as also illustrated by the similar charge injection yield obtained for both undoped and $\mathrm{Cr}$ doped materials (Fig. 6b).

The spectral signature of the photocurrent was characterized by incident photon to current conversion efficiency (IPCE) for both undoped and Cr-doped films without and with the addition of the hole scavenger (Fig. 5). Insets in this Fig. display the magnification of the onset region, showing a good correspondence between the onset wavelength for the IPCE and the absorbance of the films (Fig. 3), around $600 \mathrm{~nm}$. There is also an excellent agreement between the integrated photocurrent extracted from the IPCE spectra and that obtained from the $\mathrm{j}-\mathrm{V}$ measurements (Fig. $5 \mathrm{c}$ and d), as illustrated in Supplementary Information, Table SI1.

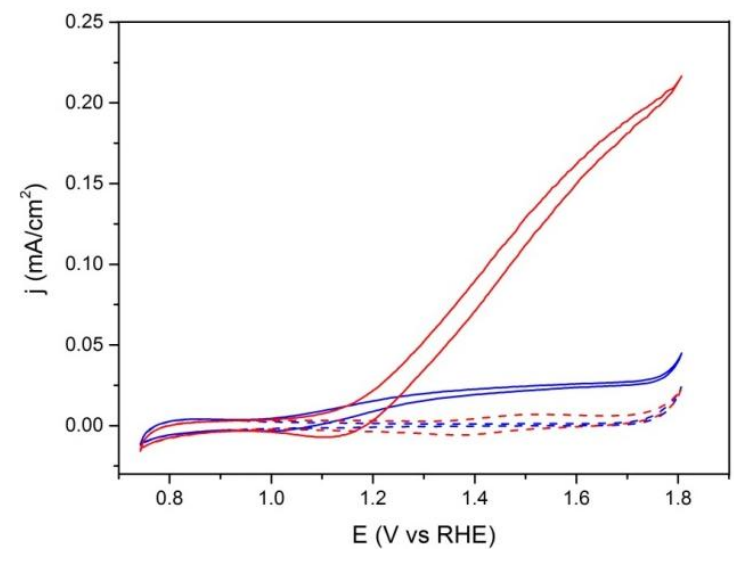

(a)

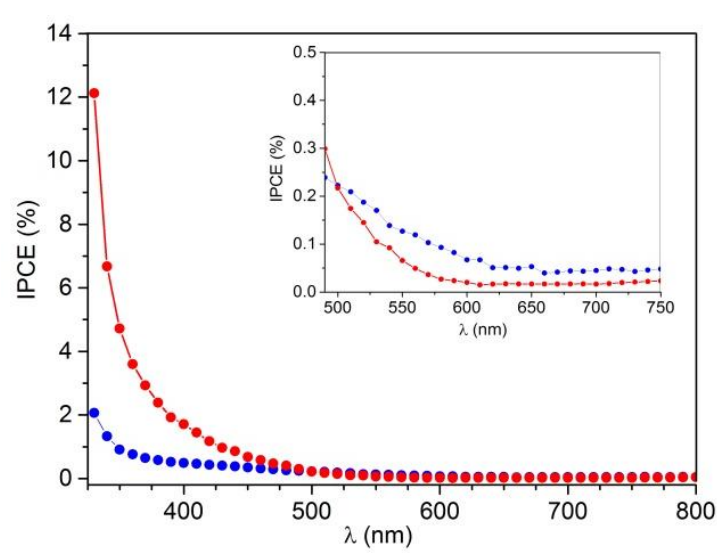

(c)

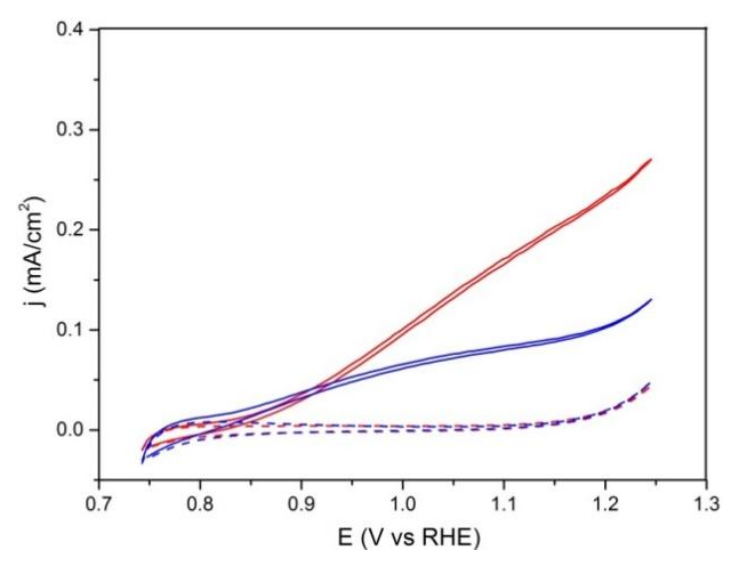

(b)

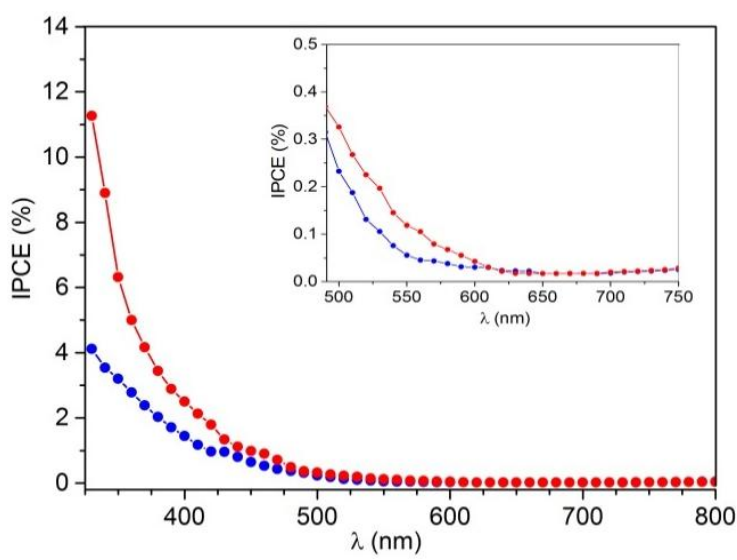

(d) 
Fig. 5. j-V curves of $800 \mathrm{~nm} \mathrm{Cu}_{3} \mathrm{~V}_{2} \mathrm{O}_{8}$ (blue lines) and $\mathrm{Cr}$ : $\mathrm{Cu}_{3} \mathrm{~V}_{2} \mathrm{O}_{8}$ (red lines) films obtained in the dark (dashed lines) and under front-side illumination at $100 \mathrm{~mW} \cdot \mathrm{cm}^{-2}$ (solid lines) in borate buffer at $\mathrm{pH} 9.2$ (a) without and (b) with hole scavenger (0.1 M $\mathrm{Na}_{2} \mathrm{SO}_{3}$ ). IPCE spectra of $800 \mathrm{~nm}$ undoped $\mathrm{Cu}_{3} \mathrm{~V}_{2} \mathrm{O}_{8}$ (blue symbols) and $\mathrm{Cr}_{2} \mathrm{Cu}_{3} \mathrm{~V}_{2} \mathrm{O}_{8}$ (red symbols) films obtained in borate buffer at $\mathrm{pH} 9.2$ (c) at $1.54 \mathrm{~V}$ vs RHE without hole scavenger and (d) at $1.0 \mathrm{~V}$ vs RHE with hole scavenger $\left(0.1 \mathrm{M} \mathrm{Na}_{2} \mathrm{SO}_{3}\right)$. The inset plots show a magnification of the onset region.

In order to quantitatively evaluate the limiting factors for performance of the synthesized materials, the two critical parameters i.e. the charge separation $\left(\eta_{c s}\right)$ and charge injection $\left(\eta_{\text {cat }}\right)$ yields were calculated for both doped and undoped oxide. In principle, the maximum photocurrent density that can be obtained if all the electron-hole pairs take part in the OER, $j_{a b s}$, can be calculated from the optical measurements by integrating the solar photon flux $\left(\Phi_{\lambda}\right.$ [photons $\left.\left./\left(\mathrm{m}^{2} \mathrm{~s}\right)\right]\right)$, from the lower limit of the measured solar spectrum to the absorption edge $(600 \mathrm{~nm})$ of the oxide: $j_{a b s}=\int\left(\Phi_{\lambda} \times q\right) d \lambda$. The calculated theoretical photocurrent was $12.90 \mathrm{~mA} \cdot \mathrm{cm}^{-2}$ and $11.21 \mathrm{~mA} \cdot \mathrm{cm}^{-2}$ for $800 \mathrm{~nm}$ thick undoped and $\mathrm{Cr}$ doped films, respectively. In aqueous electrolyte, the photocurrent density $\left(j_{\mathrm{H}_{2} \mathrm{O}}\right)$ could be affected mainly by the charge separation efficiency on the bulk material and the charge injection efficiency related with the surface kinetic reaction or catalytic efficiency [33], so that: $j_{H_{2} O}=j_{a b s} \times \eta_{c s} \times \eta_{c a t}$. In presence of the hole scavenger, we assume that the catalytic efficiency is close to unity, so the obtained photocurrent density $\left(j_{H S}\right)$ will be affected only by the charge separation efficiency: $j_{H S}=j_{a b s} \times \eta_{c s}$.

The comparative behavior of both calculated yields is showed in Fig. 6. The low $\eta_{\mathrm{cs}}$ values $(<2 \%$ ) obtained for the undoped material highlight the excessive bulk recombination losses in this material, which constitute the main limiting factor for performance. Chromium doping significantly increases $\eta_{c s}$, (with a five-fold enhancement 
at $1.23 \mathrm{~V}$ vs RHE), although the obtained values are still low for further technological deployment of this material. On the other hand, the effect of chromium doping on $\eta_{\text {cat }}$ is negligible. The addition of water oxidation co-catalysts could significantly enhance this yield, although given the high bulk recombination losses reflected in the low $\eta_{\mathrm{cs}}$ yields, further efforts towards improving the catalytic performance of this material were not attempted. It is important to highlight that the method employed to calculate $\eta_{\mathrm{cs}}$ and $\eta_{\mathrm{cat}}$ based on the use of a hole scavenger does not differentiate between improved catalysis and reduced surface recombination, which is a limitation for a more robust assessment. In any case, it provides a clear difference between bulk and surface origin of the enhanced performance and in the present study it clearly helps to understand that main origin of the enhancement produced by $\mathrm{Cr}$ doping arises from the bulk properties of the material.

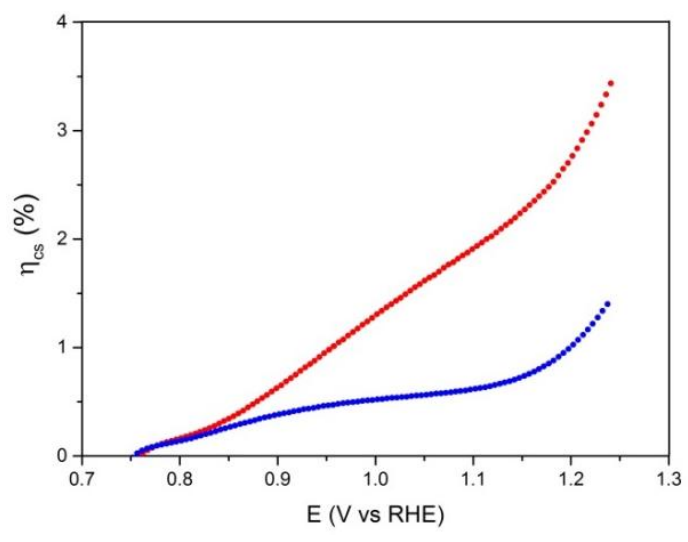

(a)

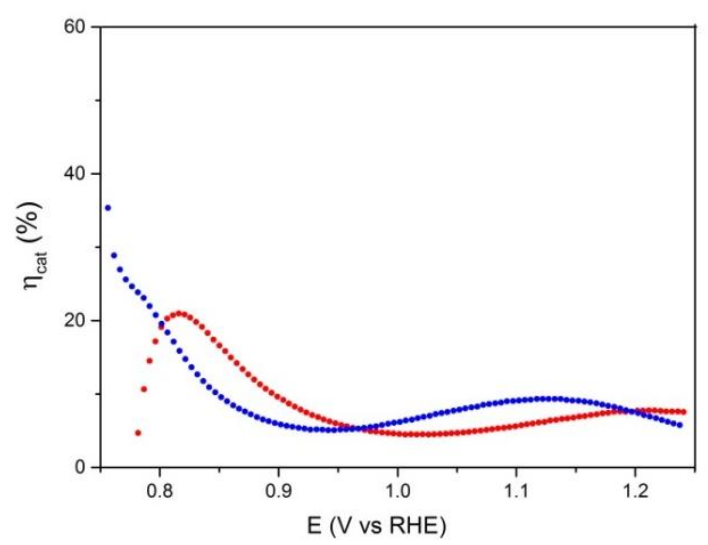

(b)

Fig. 6. (a) Charge separation efficiency $\left(\eta_{c s}\right)$ and (b) Charge injection efficiency ( $\left.\eta_{\text {cat }}\right)$ for $800 \mathrm{~nm}$ films of $\mathrm{Cu}_{3} \mathrm{~V}_{2} \mathrm{O}_{8}$ (blue) and $\mathrm{Cr} \mathrm{Cu}_{3} \mathrm{~V}_{2} \mathrm{O}_{8}$ (red).

Impedance spectroscopy (IS) measurements were carried out to assess the electronic properties of the $\mathrm{Cu}_{3} \mathrm{~V}_{2} \mathrm{O}_{8}$ photoanodes, i.e., doping density $\left(N_{D}\right)$ and flatband potential $\left(V_{f b}\right)$, by means of Mott-Schottky (MS) plots. The value for the relative dielectric permittivity ( $\varepsilon$ ) was estimated as 44.[34] This study was performed in dark conditions covering a wide potential window (from 0.5 to $1.5 \mathrm{~V}$ vs RHE) and at single frequencies (10 
$\mathrm{Hz}, 50 \mathrm{~Hz}$ and $100 \mathrm{~Hz}$, respectively). The frequencies were selected from the region at which the real part of the capacitance remained constant $(10 \mathrm{~Hz}-100 \mathrm{~Hz})$ in preliminary multi-frequency tests $(10 \mathrm{MHz}-100 \mathrm{mHz}$ ) at a constant applied bias (see Supplementary Information, Fig. SI5). Fig. 7 compares the MS plots obtained at a frequency of $10 \mathrm{~Hz}$ for doped and undoped $\mathrm{Cu}_{3} \mathrm{~V}_{2} \mathrm{O}_{8}$ films and with these plots, the values for $N_{D}$ and $V_{f b}$ were estimated. Note that identical MS plots were obtained for the measurements at $50 \mathrm{~Hz}$ and $100 \mathrm{~Hz}$ (see Supplementary Information, Fig. SI3). The lower slope reported for the $\mathrm{Cr}: \mathrm{Cu}_{3} \mathrm{~V}_{2} \mathrm{O}_{8}$ samples with $0.75 \%$ and more significantly with $1 \%$ of chromiun content is connected to an increase in the doping density (Table 1) which can be attributed to the isomorphic replacement of $\mathrm{Cu}$ (II) by $\mathrm{Cr}$ (III) in the $\mathrm{Cu}_{3} \mathrm{~V}_{2} \mathrm{O}_{8}$ lattice, analogous to the $\mathrm{V}(\mathrm{V})$ substitution by $\mathrm{Mo}(\mathrm{VI})$ reported in other vanadates.[29, 35] The statistical significance of these results is illustrated in Supplementary Information, Fig. SI6, where four identical samples were measured at each condition. The flatband potential, $V_{f b}$, for $\mathrm{Cu}_{3} \mathrm{~V}_{2} \mathrm{O}_{8}$ photoanode is $0.79 \mathrm{~V}$ vs RHE, which is slightly more positive than the frequency-dependent values previously reported (between 0.63 and $0.69 \mathrm{~V}$ vs RHE) [29]. In addition, $V_{f b}$ for the optimum Cr-doped film was around $120 \mathrm{mV}$ cathodically shifted (0.67 V vs RHE), although this beneficial displacement is not reflected on the onset potential for the photocurrent, see Fig. 5a, probably due to the excessive bulk recombination losses. It is important to highlight that these very positive flatband potentials are detrimental for technological applications and further efforts should be conducted to shift cathodically this potential. 


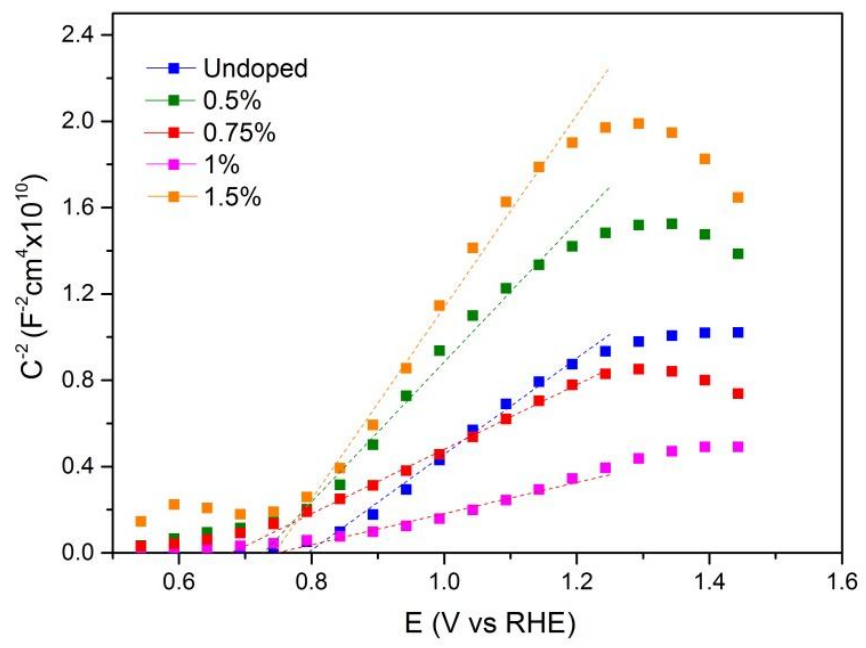

Fig. 7. Mott-Schottky plot of $\mathrm{Cu}_{3} \mathrm{~V}_{2} \mathrm{O}_{8}$ and $\mathrm{Cr}: \mathrm{Cu}_{3} \mathrm{~V}_{2} \mathrm{O}_{8}$ films performed at $10 \mathrm{~Hz}$ in borate buffer at $\mathrm{pH} 9.2$ and the lineal fitting showing the $\mathrm{x}$-intercept corresponding to the flatband potential value, $V_{f b}$.

By substitutional $\mathrm{Cr}$ doping, replacing part of the $\mathrm{Cu}$ sites, the Fermi level of copper vanadate shifts towards the conduction band increasing the band bending at the semiconductor liquid junction and consequently enhancing charge separation (Fig. 6a). This has a beneficial effect on the photoelectrochemical performance. On the other hand, there is an anomaly on the donor density for $0.5 \%$ and $1.5 \% \mathrm{Cr}$ additions. EDS and XPS experiments were carried out to understand the correlation between added $\mathrm{Cr}$ during the synthetic process and incorporated $\mathrm{Cr}$ into the specimens. Unfortunately the $\mathrm{Cr}$ contents employed are below the detection limit of these techniques and further information could not be obtained. XRD analysis did not show the presence of secondary phases at any $\mathrm{Cr}$ concentration tested, but a significant shift of the maximum on the [012] direction (Fig. 1) was registered at the highest concentration (1.5\%), which could be related to a degradation of the film integrity as result of the strain induced by $\mathrm{Cr}$ replacing $\mathrm{Cu}$ positions into the periodic crystal lattice, with the consequent progressive decrease of the photocurrent showed in Fig. 4b for high $\mathrm{Cr}$ additions. In any case, further work is needed to understand the anomaly at the lowest $\mathrm{Cr}$ addition $(0.5 \%)$. The morphological modification of the 
electrodes with $\mathrm{Cr}$ addition, illustrated by Supplementary Information, Fig. SI7 could slightly affect the donor densities measured, but it is not believed to the main reason explaining the observed behavior.

Table 1. Estimated dopant density and flat band potential of $\mathrm{Cu}_{3} \mathrm{~V}_{2} \mathrm{O}_{8}$ and $\mathrm{Cr}: \mathrm{Cu}_{3} \mathrm{~V}_{2} \mathrm{O}_{8}$ from the MS plots at $10 \mathrm{~Hz}$.

\begin{tabular}{cccccc}
\hline & & \multicolumn{5}{c}{$\mathrm{Cr}: \mathrm{Cu}_{3} \mathrm{~V}_{2} \mathrm{O}_{8}$} \\
& $\mathrm{Cu}_{3} \boldsymbol{V}_{2} \mathrm{O}_{8}$ & $\mathbf{0 . 5 \%}$ & $\mathbf{0 . 7 5 \%}$ & $\mathbf{1 \%}$ & $\mathbf{1 . 5 \%}$ \\
\hline $\boldsymbol{N}_{\boldsymbol{D}}\left(\mathbf{1 0}^{\mathbf{2 0}} \mathbf{c m}^{-3}\right)$ & 1.44 & 0.99 & 2.20 & 4.44 & 0.72 \\
\hline$V_{f b}(V)$ & 0.79 & 0.73 & 0.70 & 0.75 & 0.74 \\
\hline
\end{tabular}

In order to evaluate the stability of these films, chronoamperometric measurements were performed at $1.23 \mathrm{~V}$ vs RHE for $1 \mathrm{~h}$ (Fig. 8), finding a very stable behavior of photocurrent response, with an overall loss of around the $14 \%$ at the end of the measurement with respect the five initial minutes for the measures with hole scavenger. The higher losses observed in the measurements performed in presence of the hole scavenger is related with the fact that the rapid removal of the photogenerated holes at the surface by the sulfite can compete with photocorrosion process, which was reported indeed in Mo-doped copper vanadates as well[29]. This remarks the fact that, for better performance of this material, an appropriated surface modification with a suitable oxygen reaction catalyst that can also avoid direct contact of the semiconductor surface with the electrolyte to prevent photocorrossion, is needed. 


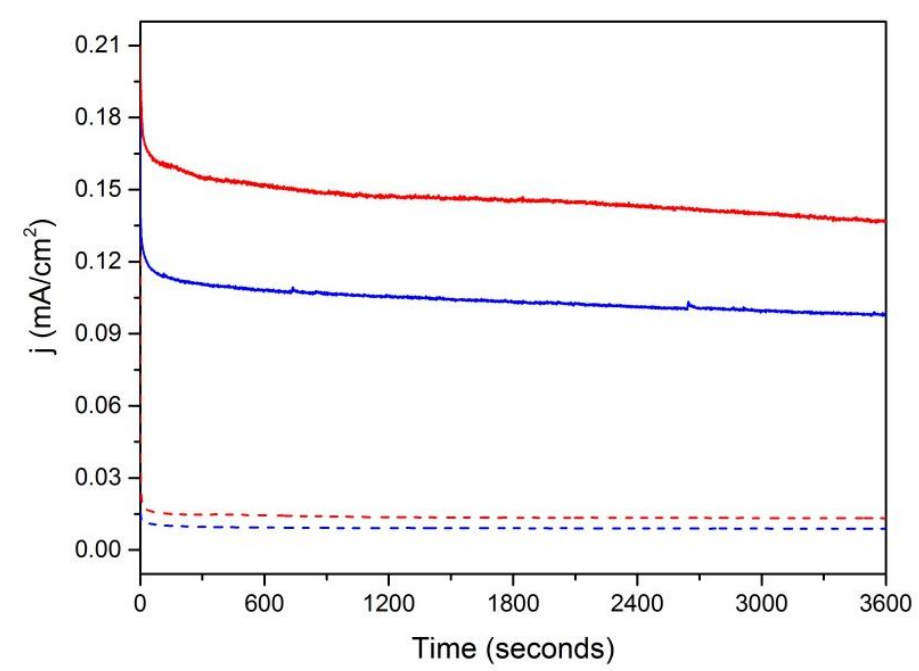

Fig. 8 Potentiostatic photocurrent of $\mathrm{Cu}_{3} \mathrm{~V}_{2} \mathrm{O}_{8}$ (blue) and $\mathrm{Cr}: \mathrm{Cu}_{3} \mathrm{~V}_{2} \mathrm{O}_{8}$ (red) films at 1.23 $\mathrm{V}$ vs RHE in borate buffer at $\mathrm{pH} 9.2$ without (dashed lines) and with $0.1 \mathrm{M} \mathrm{Na}_{2} \mathrm{SO}_{3}$ (solid lines).

Finally, in order to confirm that the obtained photocurrent actually stems from water oxidation, the $\mathrm{O}_{2}$ evolution on $\mathrm{Cr}_{2} \mathrm{Cu}_{3} \mathrm{~V}_{2} \mathrm{O}_{8}$ (0.75 at. \% of $\mathrm{Cr}$ content) electrodes was determined by performing chronoamperometric measurements at $1.54 \mathrm{~V}$ vs RHE under 1 sun illumination in a sealed cell, and the output gas flow was analyzed by chromatography. From the chronoamperometric measurement the theoretical $\mathrm{O}_{2}$ production was estimated through the Faraday's law, as represented in Fig. 9a (black line) and compared with the measured values (red symbols). Because of the dispersion on the obtained values, related with imperfections on the manual sampling during the chromatography analysis, a linear fitting is represented for a better comparison. The measured $\mathrm{O}_{2}$ produced in this photoanode correlate well with respect the theoretical estimated, being the faradic efficiency $>90 \%$ after $1 \mathrm{~h}$, as is represented in Fig. 9b. The fact that there is not reached a $100 \%$ of faradic efficiency must likely related with photocorrosion process of the semiconductor in contact with the electrolyte, which have been also observed in $\mathrm{BiVO}_{4}{ }^{-}$ based photoanodes, were the faradic efficiency losses have been related with imperfect coverage of the semiconductor surface by the catalyst material[36], which remarks the 
need to employ this kind of strategies in further investigations in order to improve the photocatalytic feature of this semiconductor and achieve competitive efficiency performance.

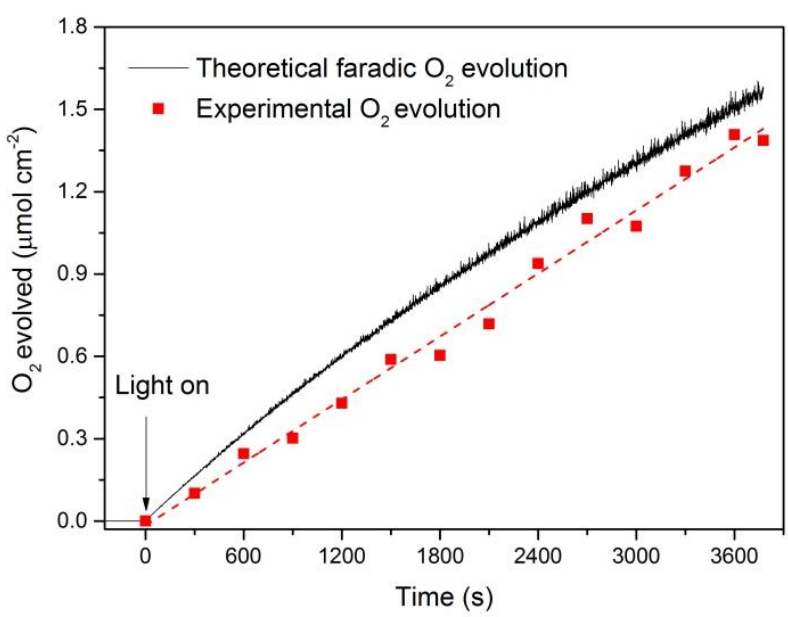

(a)

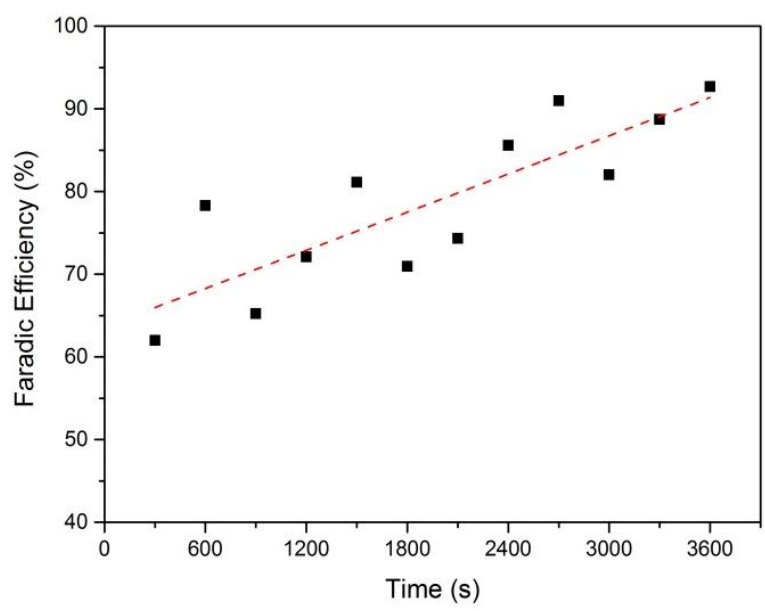

(b)

Fig. 9. (a) Oxygen evolution in borate buffer at pH 9.2 measured under continuous 1 sun irradiation at $1.54 \mathrm{~V}$ versus RHE registered experimentally by gas chromatography (red squares) and theoretically calculated from the measured current by the Faraday's law (black line). (b) Faradic efficiency obtained from comparing the theoretical and experimental oxygen evolution showed in (a).

\section{Conclusions}

In summary, we have studied the optical and photoelectrochemical properties of $\mathrm{Cu}_{3} \mathrm{~V}_{2} \mathrm{O}_{8}$ as a candidate photoanode for photoelectrochemical water splitting and explored the effect of $\mathrm{Cr}$ doping aiming at overcoming the large bulk recombination losses in this material. Our results show that although a remarkable improvement is photocurrent is obtained after 0.75 at.\% $\mathrm{Cr}$ doping, which can be related to an increased extrinsic doping of the material, further efforts must be carried out in order to achieve competitive charge separation yields (>70\%) for technological deployment. Additionally, the flatband should 
be shifted to more cathodic potentials to allow the exploration of alternative configurations

based on n-n heterojunctions.

\section{Acknowledgements}

We thank financial support from the University Jaume I through the project

P1.1B2011-50 and from the Generalitat Valenciana, through the project

PROMETEOII/2014/020 and the Santiago Grisolia Program, grant 2015-031. Serveis

Centrals at UJI (SCIC) are also acknowledged.

\section{References}

[1] P.V. Kamat, Meeting the Clean Energy Demand: Nanostructure Architectures for Solar Energy Conversion, The Journal of Physical Chemistry C 111 (2007) 2834-2860.

[2] K. Sivula, Metal Oxide Photoelectrodes for Solar Fuel Production, Surface Traps, and Catalysis, The Journal of Physical Chemistry Letters 4 (2013) 16241633.

[3] S. Cho, J.-W. Jang, K.-H. Lee, J.S. Lee, Research Update: Strategies for efficient photoelectrochemical water splitting using metal oxide photoanodes, APL Mater. 2 (2014) 010703.

[4] A. Fujishima, K. Honda, Electrochemical Photolysis of Water at a Semiconductor Electrode, Nature 238 (1972) 37-38.

[5] J. Nowotny, T. Bak, M.K. Nowotny, L.R. Sheppard, Titanium dioxide for solarhydrogen I. Functional properties, International Journal of Hydrogen Energy 32 (2007) 2609-2629.

[6] K. Sivula, F. LeFormal, M. Grätzel, Solar Water Splitting: Progress Using Hematite $\left(\alpha-\mathrm{Fe}_{2} \mathrm{O}_{3}\right)$ Photoelectrodes, ChemSusChem 4 (2011) 432-449.

[7] M.A. Butler, Photoelectrolysis and physical properties of the semiconducting electrode $\mathrm{WO}_{2}$ Journal of Applied Physics 48 (1977) 1914-1920.

[8] A. Wolcott, W.A. Smith, T.R. Kuykendall, Y. Zhao, J.Z. Zhang, Photoelectrochemical Study of Nanostructured ZnO Thin Films for Hydrogen Generation from Water Splitting, Advanced Functional Materials 19 (2009) $1849-1856$.

[9] A. Kudo, K. Omori, H. Kato, A novel aqueous process for preparation of crystal form-controlled and highly crystalline $\mathrm{BiVO}_{4}$ powder from layered vanadates at room temperature and its photocatalytic and photophysical properties, Journal of the American Chemical Society 121 (1999) 11459-11467.

[10] K. Sayama, A. Nomura, Z. Zou, R. Abe, Y. Abe, H. Arakawa, Photoelectrochemical decomposition of water on nanocrystalline $\mathrm{BiVO}_{4}$ film electrodes under visible light, Chemical Communications (2003) 2908-2909.

[11] C. Santato, M. Ulmann, J. Augustynski, Photoelectrochemical Properties of Nanostructured Tungsten Trioxide Films, The Journal of Physical Chemistry B 105 (2001) 936-940. 
[12] M. Woodhouse, B.A. Parkinson, Combinatorial approaches for the identification and optimization of oxide semiconductors for efficient solar photoelectrolysis, Chemical Society Reviews 38 (2009) 197-210.

[13] F.F. Abdi, L. Han, A.H.M. Smets, M. Zeman, B. Dam, R. van de Krol, Efficient solar water splitting by enhanced charge separation in a bismuth vanadatesilicon tandem photoelectrode, Nature Communications 4 (2013).

[14] L. Steier, I. Herraiz-Cardona, S. Gimenez, F. Fabregat-Santiago, J. Bisquert, S.D. Tilley, M. Graetzel, Understanding the Role of Underlayers and Overlayers in Thin Film Hematite Photoanodes, Advanced Functional Materials 24 (2014) 7681-7688.

[15] C. Du, X. Yang, M.T. Mayer, H. Hoyt, J. Xie, G. McMahon, G. Bischoping, D. Wang, Hematite-Based Water Splitting with Low Turn-On Voltages, Angewandte Chemie-International Edition 52 (2013) 12692-12695.

[16] O. Zandi, T.W. Hamann, Enhanced Water Splitting Efficiency Through Selective Surface State Removal, Journal of Physical Chemistry Letters 5 (2014) $1522-1526$.

[17] T.W. Kim, K.-S. Choi, Nanoporous BiVO 4 Photoanodes with Dual-Layer Oxygen Evolution Catalysts for Solar Water Splitting, Science 343 (2014) 990994.

[18] J. Suntivich, K.J. May, H.A. Gasteiger, J.B. Goodenough, Y. Shao-Horn, A Perovskite Oxide Optimized for Oxygen Evolution Catalysis from Molecular Orbital Principles, Science 334 (2011) 1383-1385.

[19] Y. Pihosh, I. Turkevych, K. Mawatari, T. Asai, T. Hisatomi, J. Uemura, M. Tosa, K. Shimamura, J. Kubota, K. Domen, T. Kitamori, Nanostructured $\mathrm{WO}_{3} / \mathrm{BiVO}_{4}$ Photoanodes for Efficient Photoelectrochemical Water Splitting, Small 10 (2014) 3692-3699.

[20] I. Cesar, A. Kay, J.A.G. Martinez, M. Gratzel, Translucent thin film $\mathrm{Fe}_{2} \mathrm{O}_{3}$ photoanodes for efficient water splitting by sunlight: Nanostructure-directing effect of Si-doping, Journal of the American Chemical Society 128 (2006) 45824583.

[21] F.E. Osterloh, Inorganic nanostructures for photoelectrochemical and photocatalytic water splitting, Chemical Society Reviews 42 (2013) 2294-2320.

[22] Y. Lin, S. Zhou, S.W. Sheehan, D. Wang, Nanonet-Based Hematite Heteronanostructures for Efficient Solar Water Splitting, Journal of the American Chemical Society 133 (2011) 2398-2401.

[23] X. Shi, Y. Choi, K. Zhang, J. Kwon, D.Y. Kim, J.K. Lee, S.H. Oh, J.K. Kim, J.H. Park, Efficient photoelectrochemical hydrogen production from bismuth vanadate-decorated tungsten trioxide helix nanostructures, Nature Communications 5 (2014).

[24] X. Shi, K. Zhang, K. Shin, M. Ma, J. Kwon, I.T. Choi, J.K. Kim, H.K. Kim, D.H. Wang, J.H. Park, Unassisted photoelectrochemical water splitting beyond $5.7 \%$ solar-to-hydrogen conversion efficiency by a wireless monolithic photoanode/dye-sensitised solar cell tandem device, Nano Energy 13 (2015) 182-191.

[25] Y. Pihosh, I. Turkevych, K. Mawatari, J. Uemura, Y. Kazoe, S. Kosar, K. Makita, T. Sugaya, T. Matsui, D. Fujita, M. Tosa, M. Kondo, T. Kitamori, Photocatalytic generation of hydrogen by core-shell $\mathrm{WO}_{3} / \mathrm{BiVO}_{4}$ nanorods with ultimate water splitting efficiency, Scientific Reports 5 (2015) 11141. 
[26] H.X. Dang, A.J.E. Rettie, C.B. Mullins, Visible-Light-Active $\mathrm{NiV}_{2} \mathrm{O}_{6}$ Films for Photoelectrochemical Water Oxidation, The Journal of Physical Chemistry C 119 (2015) 14524-14531.

[27] S. Zhang, Y. Sun, C. Li, L. Ci, $\mathrm{Cu}_{3} \mathrm{~V}_{2} \mathrm{O}_{8}$ hollow spheres in photocatalysis and primary lithium batteries, Solid State Sciences 25 (2013) 15-21.

[28] J. Dai, M. Lai, R.M. LaFollette, D. Reisner, Thin Film Copper Vanadium Oxide Electrodes for Thermal Batteries, ECS Transactions 33 (2011) 3-9.

[29] J.A. Seabold, N.R. Neale, All First Row Transition Metal Oxide Photoanode for Water Splitting Based on $\mathrm{Cu}_{3} \mathrm{~V}_{2} \mathrm{O}_{8}$, Chemistry of Materials 27 (2015) 10051013.

[30] W. Guo, W.D. Chemelewski, O. Mabayoje, P. Xiao, Y. Zhang, C.B. Mullins, Synthesis and Characterization of $\mathrm{CuV}_{2} \mathrm{O}_{6}$ and $\mathrm{Cu}_{2} \mathrm{~V}_{2} \mathrm{O}_{7}$ : Two Photoanode Candidates for Photoelectrochemical Water Oxidation, The Journal of Physical Chemistry C 119 (2015) 27220-27227.

[31] L. Zhou, Q. Yan, J. Yu, R.J.R. Jones, N. Becerra-Stasiewicz, S.K. Suram, A. Shinde, D. Guevarra, J.B. Neaton, K.A. Persson, J.M. Gregoire, Stability and self-passivation of copper vanadate photoanodes under chemical, electrochemical, and photoelectrochemical operation, Physical Chemistry Chemical Physics 18 (2016) 9349-9352.

[32] T. Hisatomi, J. Kubota, K. Domen, Recent advances in semiconductors for photocatalytic and photoelectrochemical water splitting, Chemical Society Reviews 43 (2014) 7520-7535.

[33] H. Dotan, K. Sivula, M. Graetzel, A. Rothschild, S.C. Warren, Probing the photoelectrochemical properties of hematite $\left(\alpha-\mathrm{Fe}_{2} \mathrm{O}_{3}\right)$ electrodes using hydrogen peroxide as a hole scavenger, Energy \& Environmental Science 4 (2011) 958-964.

[34] S. Sarkar, K.K. Chattopadhyay, Size-dependent optical and dielectric properties of $\mathrm{BiVO}_{4}$ nanocrystals, Physica E: Low-dimensional Systems and Nanostructures 44 (2012) 1742-1746.

[35] W.-J. Yin, S.-H. Wei, M.M. Al-Jassim, J. Turner, Y. Yan, Doping properties of monoclinic $\mathrm{BiVO}_{4}$ studied by first-principles density-functional theory, Physical Review B 83 (2011) 155102.

[36] J.A. Seabold, K.-S. Choi, Efficient and Stable Photo-Oxidation of Water by a Bismuth Vanadate Photoanode Coupled with an Iron Oxyhydroxide Oxygen Evolution Catalyst, Journal of the American Chemical Society 134 (2012) 21862192. 


\section{Supplementary Information}

\section{Chromium doped copper vanadates photoanodes for water splitting}

\section{Drialys Cardenas-Morcoso, Anna Peiro-Franch, Isaac Herraiz-Cardona, Sixto Gimenez*}

Institute of Advanced Materials (INAM), Universitat Jaume I, 12006 Castelló, Spain

Email: sjulia@uji.es

12 October 2016

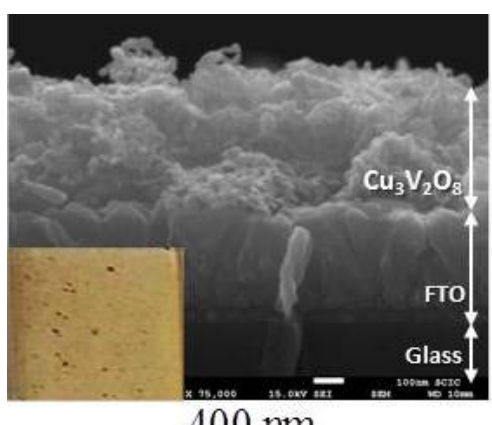

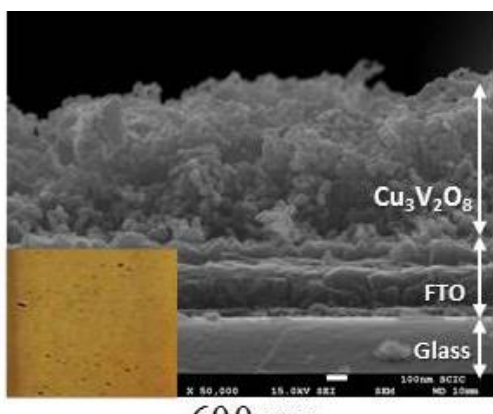

$600 \mathrm{~nm}$

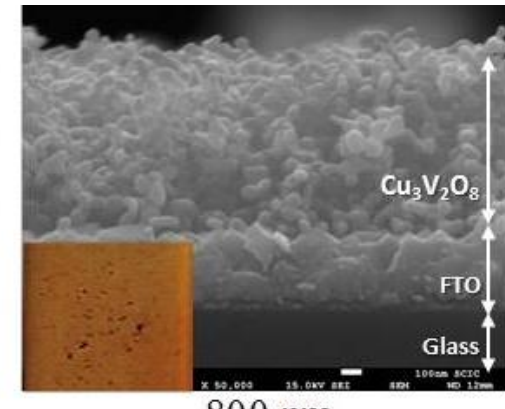

$800 \mathrm{~nm}$

Figure SI1. Cross sections of the $\mathrm{Cu}_{3} \mathrm{~V}_{2} \mathrm{O}_{8}$ thin films after $425{ }^{\circ} \mathrm{C}$ annealing with different thickness values as a result of the number of deposited layers during the spin coating. The scale bar is $100 \mathrm{~nm}$ in all micrographs.

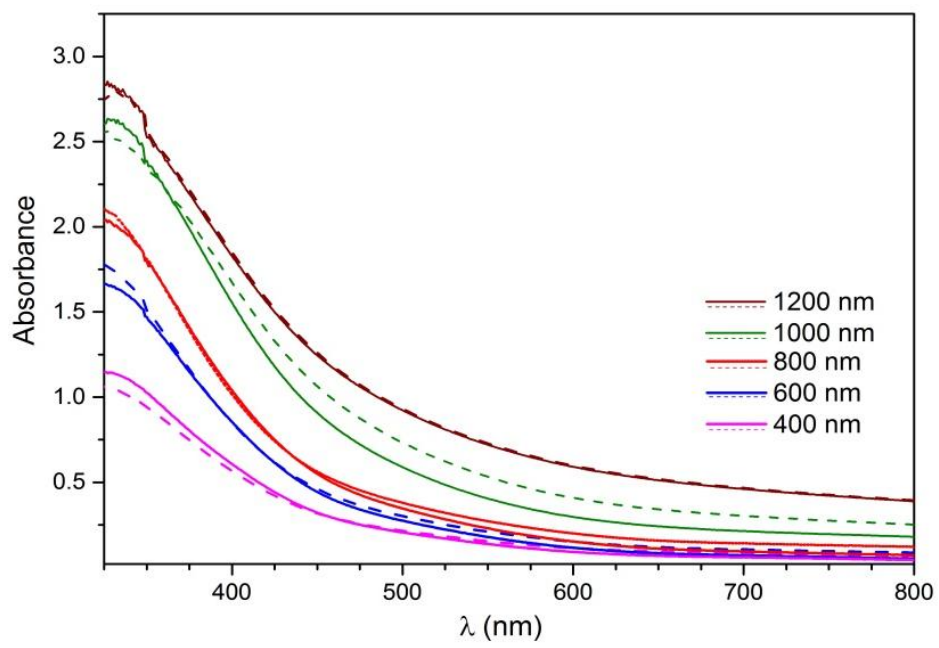

Figure SI2. Absorbance of $\mathrm{Cu}_{3} \mathrm{~V}_{2} \mathrm{O}_{8}$ (dashed lines) and $\mathrm{Cr}: \mathrm{Cu}_{3} \mathrm{~V}_{2} \mathrm{O}_{8}(0.75 \%$ ) (solid lines) with different thickness values. 


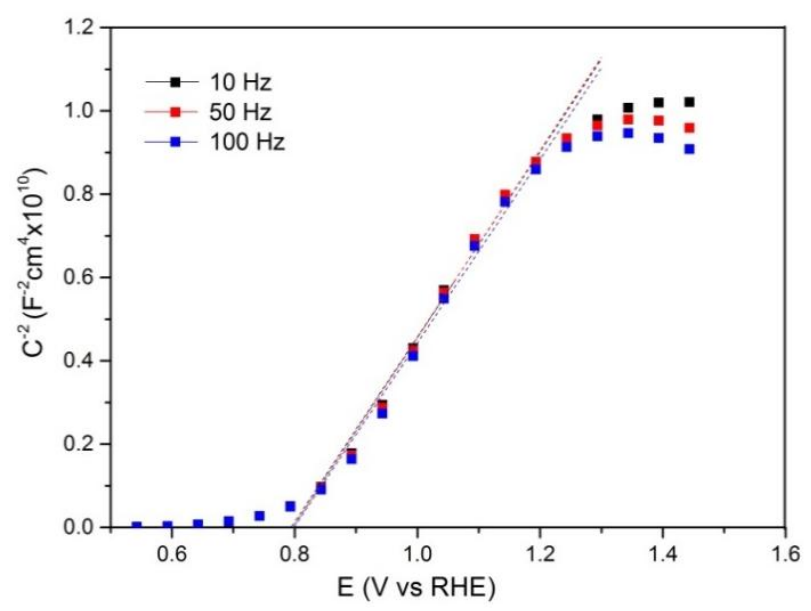

Figure SI3. Mott-Schottky plot of $600 \mathrm{~nm} \mathrm{Cu} \mathrm{V}_{2} \mathrm{O}_{8}$ films performed at $10 \mathrm{~Hz}, 50 \mathrm{~Hz}$ and $100 \mathrm{~Hz}$ in borate buffer at $\mathrm{pH} 9.2$ and the corresponding lineal fitting showing the $x$-intercept.

\section{$0.5 \%$}

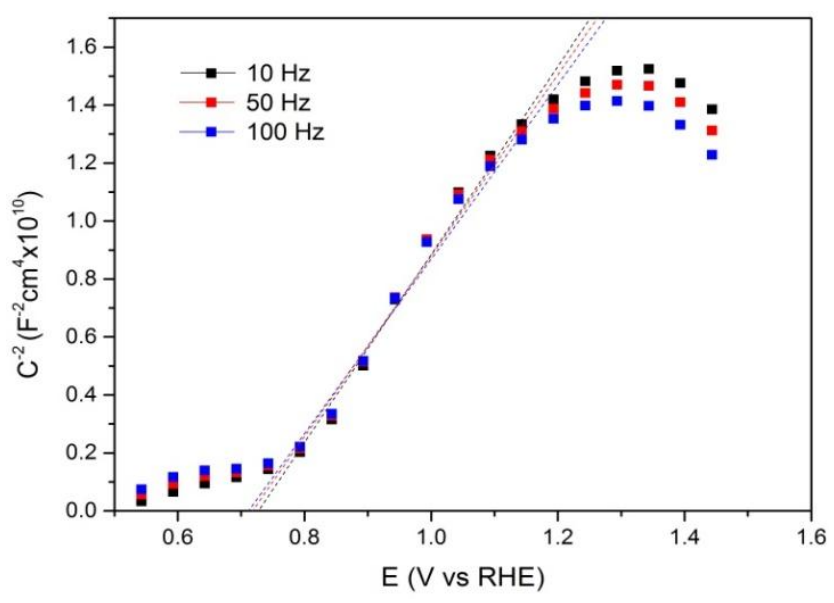

$1 \%$

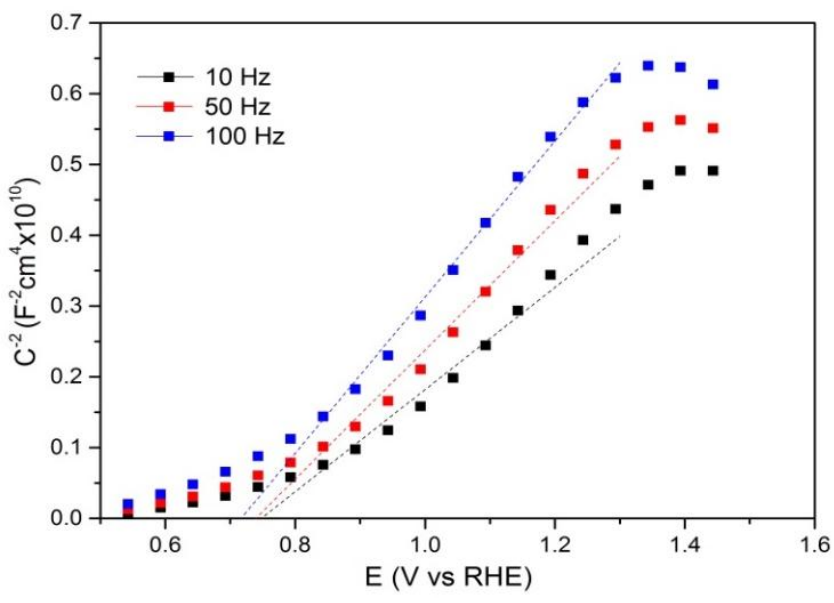

$0.75 \%$

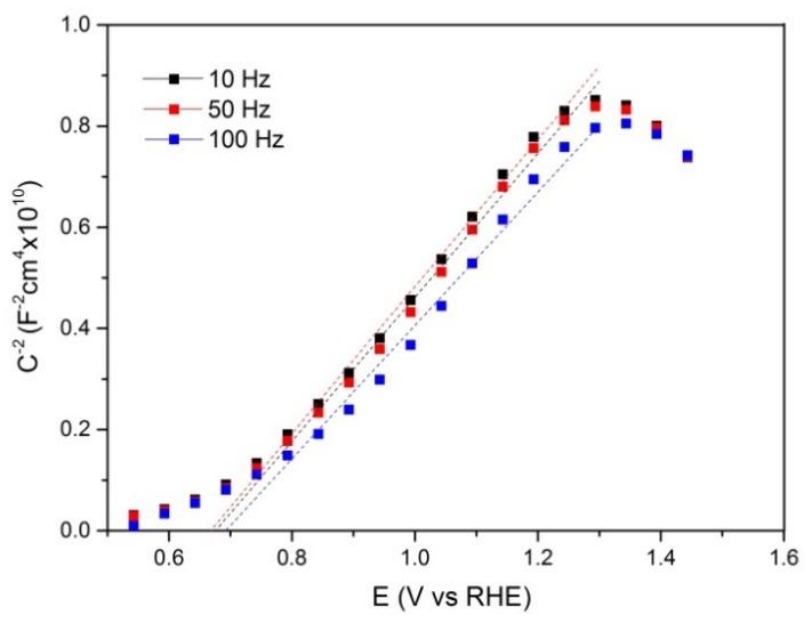

$1.5 \%$

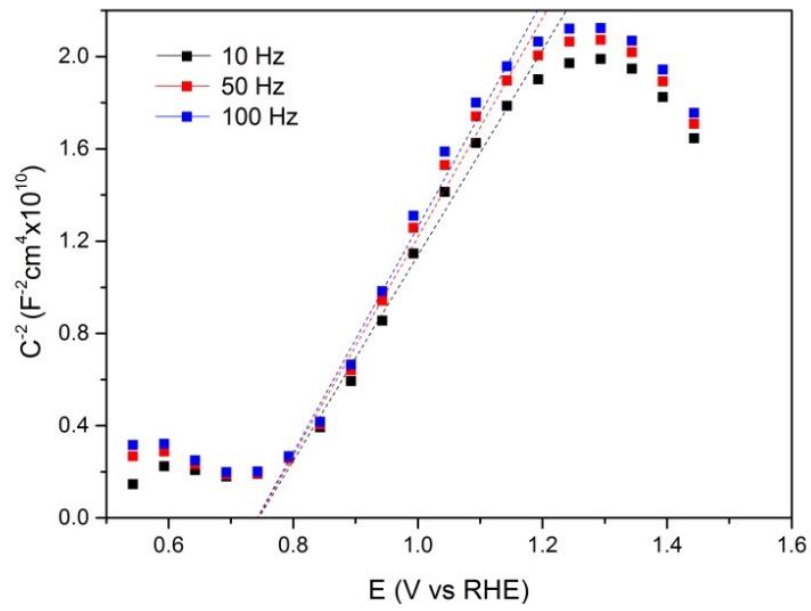

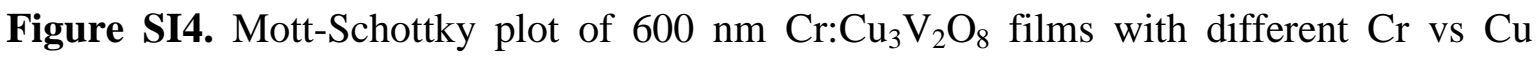
content performed at $10 \mathrm{~Hz}, 50 \mathrm{~Hz}$ and $100 \mathrm{~Hz}$ in borate buffer at $\mathrm{pH} 9.2$ and the corresponding lineal fitting showing the $x$-intercept (flatband potential). 


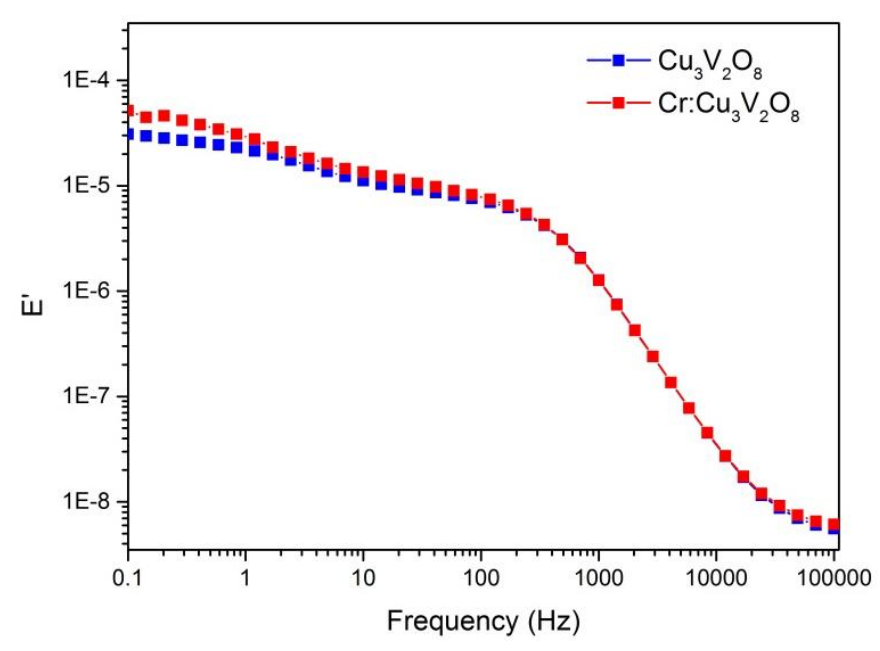

Figure SI5. Bode plots of the impedance spectra obtained in borate buffer at $\mathrm{pH} 9.2$ and dark conditions, at $1.54 \mathrm{~V}$ vs RHE. The frequencies employed for Mott-Schottky analysis were selected from the region where the real part of the capacitance (E') remained constant $(10-100 \mathrm{~Hz})$.

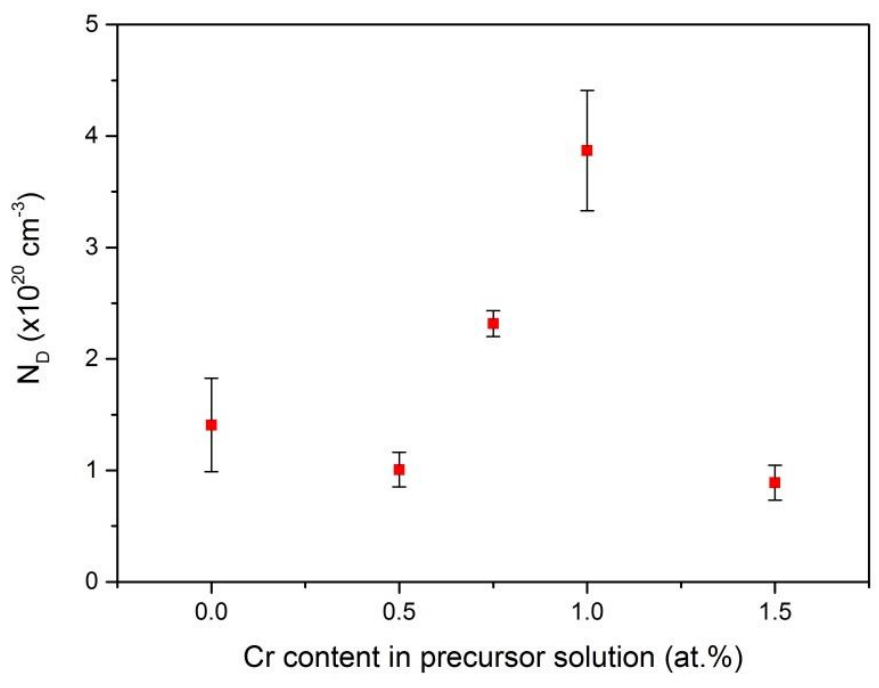

Figure SI6. $\mathrm{N}_{\mathrm{D}}$ obtained as function of $\mathrm{Cr}$ content in the precursor solution. Four samples were tested at each condition and the error bars are indicated. 

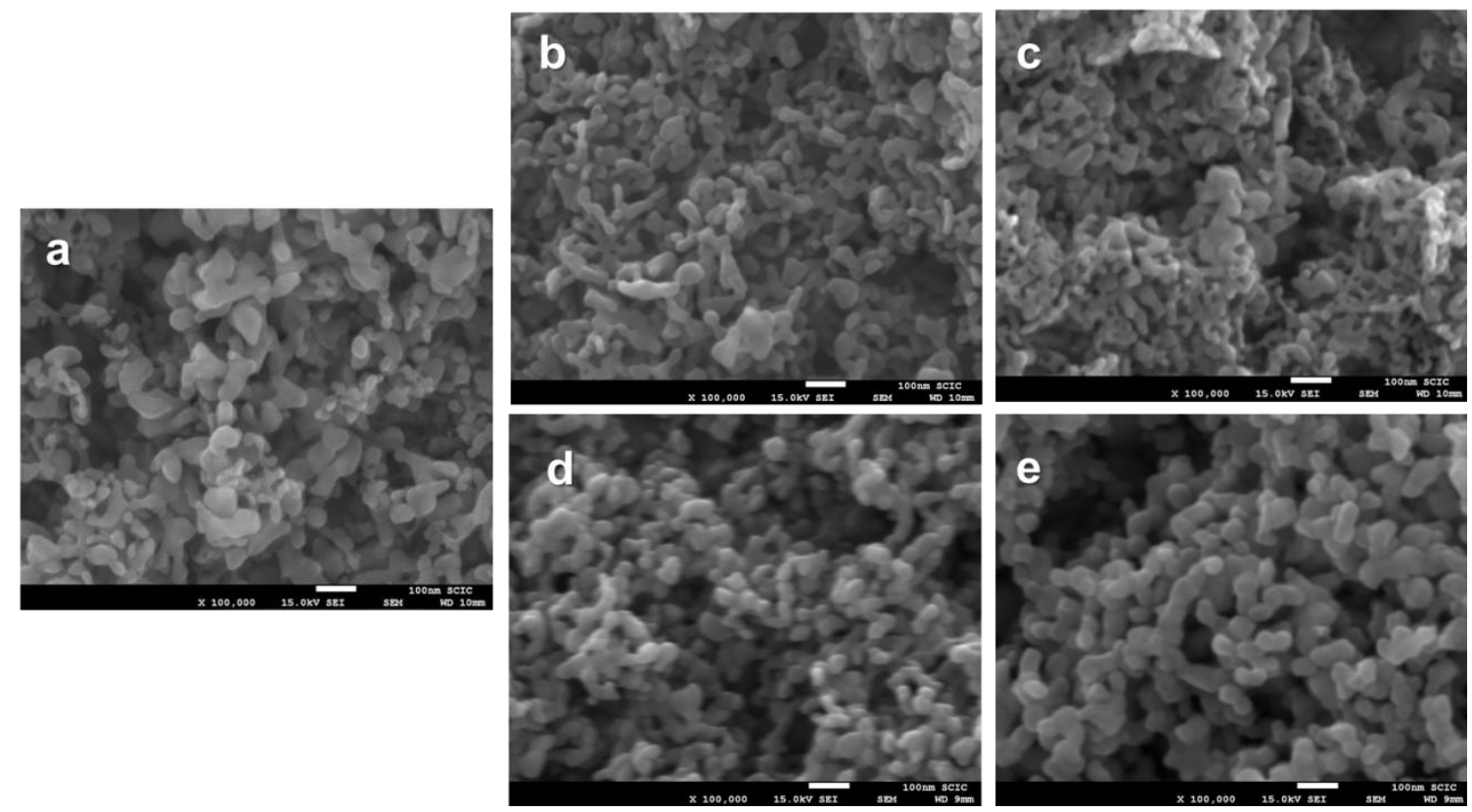

Figure SI7. Top-view of a) $\mathrm{Cu}_{3} \mathrm{~V}_{2} \mathrm{O}_{8}$, b-e) $\mathrm{Cr}$ : $\mathrm{Cu}_{3} \mathrm{~V}_{2} \mathrm{O}_{8}$ with $0.5 \%, 0.75 \%, 1 \%$ and $1.5 \%$ of $\mathrm{Cr}$ content in the precursor solution respectively, showing the effect of doping in the surface area. Scale bar is $100 \mathrm{~nm}$ in all micrographs.

Table SI1. Integrated currents from IPCE records compared with those obtained from the $\mathrm{j}-\mathrm{V}$ curves. (Reported values are obtained at $1.54 \mathrm{~V}$ vs RHE and at $1 \mathrm{~V}$ vs RHE for water oxidation and hole scavenger oxidation, respectively).

\begin{tabular}{|l|c|c|}
\hline & $\begin{array}{c}\text { Integrated Current } \\
\left(\mu \mathbf{A} / \mathbf{c m}^{2}\right)\end{array}$ & $\begin{array}{c}\text { Experimental Current } \\
\left(\mu \mathbf{A} / \mathbf{c m}^{2}\right)\end{array}$ \\
\hline $\mathrm{Cu}_{3} \mathrm{~V}_{2} \mathrm{O}_{8}$ & 24 & 25 \\
\hline $\begin{array}{l}\mathrm{Cu}_{3} \mathrm{~V}_{2} \mathrm{O}_{8} \\
\left(\text { in } 0.1 \mathrm{M} \mathrm{Na}_{2} \mathrm{SO}_{3)}\right.\end{array}$ & 52 & 67 \\
\hline $\mathrm{Cr}_{\mathrm{Cu}_{3} \mathrm{~V}_{2} \mathrm{O}_{8}}$ & 114 & 113 \\
\hline $\begin{array}{l}\mathrm{Cr}: \mathrm{Cu}_{3} \mathrm{~V}_{2} \mathrm{O}_{8} \\
\left(\text { in } 0.1 \mathrm{M} \mathrm{Na}_{2} \mathrm{SO}_{3)}\right.\end{array}$ & 123 & 102 \\
\hline
\end{tabular}

